\title{
An intergroup approach to collective narcissism: Intergroup threats and hostility in four European Union countries
}

Group Processes \& Intergroup Relations 2022, Vol. 25(2) 415-433 (C) The Author(s) 2020

Article reuse guidelines: sagepub.com/journals-permissions DOI: $10.1177 / 1368430220972178$ journals.sagepub.com/home/gpi

@SAGE

\section{Rita Guerra, ${ }^{1}$ (D) Kinga Bierwiaczonek, ${ }^{2}$ Marina Ferreira, ${ }^{1}$ Agnieszka Golec de Zavala, ${ }^{1,3,4}$ Georgios Abakoumkin, ${ }^{5}$ (D) Tim Wildschut ${ }^{6}$ and Constantine Sedikides ${ }^{6}$}

\begin{abstract}
Although it is known that collective narcissism is associated with problematic intergroup relations, its predictors are less well understood. Two studies, conducted in four European Union countries (Germany, Greece, Portugal, the United Kingdom [UK]), tested the hypotheses that integrated (i.e., realistic and symbolic) threat (Study $1, N=936$ ) as well as distinctiveness threat (Study 2, $N=434$ ) positively predict national collective narcissism and national ingroup satisfaction, but that only national collective narcissism predicts problematic intergroup relations in reference to threatening outgroups. The results were consistent with those hypotheses. The two types of threat predicted increased national collective narcissism and national ingroup satisfaction. However, only national collective narcissism was associated with negative emotions and hostile behavioral intentions toward the threatening outgroups, when its overlap with national ingroup satisfaction was partialled out. These cross-national findings advanced knowledge of predictors, as well as consequences, of collective narcissism.
\end{abstract}

\section{Keywords}

collective narcissism, ingroup satisfaction, intergroup hostility, intergroup relations, intergroup threat

Paper received 18 November 2019; revised version accepted 19 October 2020.

Collective narcissism is the belief that one's own group (the ingroup), although exceptional, is not sufficiently recognized by others (Golec de Zavala et al., 2009). Collective narcissism is a form of ingroup positivity that is associated with negative intergroup relations independently of other robust predictors such as social dominance orientation, right-wing authoritarianism, nationalism, or ingroup glorification (Cichocka, 2016; Golec de Zavala et al., 2019; Golec de Zavala \& Lantos, 2020). Although the negative intergroup

\footnotetext{
${ }^{1}$ Instituto Universitário de Lisboa (ISCTE-IUL), Portugal ${ }^{2}$ University of Oslo, Norway

${ }^{3}$ Goldsmiths, University of London, UK

${ }^{4}$ University SWPS, Poland

${ }^{5}$ University of Thessaly, Greece

${ }^{6}$ University of Southampton, UK

Corresponding author:

Rita Guerra, Instituto Universitário de Lisboa, ISCTE-IUL, CIS-IUL, Edifício ISCTE - IUL, Av. das Forças Armadas, Lisboa, 1649-026, Portugal.

Email: guerra.ar@gmail.com
} 
consequences of collective narcissism are well established, its intergroup predictors are not well understood. In this article, we extend prior work by adopting an intergroup lens to examine predictors of collective narcissism and its harmful downstream consequences. We consider not only collective narcissism but also another form of ingroup positivity, ingroup satisfaction (i.e., "one's positive feelings about the group and one's membership in it"; Leach et al., 2008, p. 146), given that forms of ingroup positivity may be differentially linked to intergroup relations (Cichocka, 2016; Golec de Zavala et al., 2020). We compare collective narcissism and ingroup satisfaction, because they pertain to the self-investment (i.e., positive feelings about and salience of ingroup membership, and solidarity with other members; Leach et al., 2008) aspect of social identification (i.e., the degree to which people's membership in a social group is "psychologically affecting and socially consequential”; Leach et al., 2008, p. 144).

Building on proposals that intergroup threats strengthen positive identification with the threatened ingroup (rejection identification model: Branscombe, Schmitt, \& Harvey, 1999; threat identification model: Schmid \& Muldoon, 2015), we examine for the first time (a) the relation of different intergroup threats (integrated and distinctiveness) with collective narcissism and ingroup satisfaction; and (b) whether collective narcissism (but not ingroup satisfaction) mediates the positive relations between intergroup threat and intergroup hostility in four European Union (EU) countries. We are interested, then, in two forms of national ingroup positivity, that is, national collective narcissism and national ingroup satisfaction (for brevity, we will refer to them as collective narcissism and ingroup satisfaction).

\section{An Intergroup Approach to Collective Narcissism}

Collective narcissism has detrimental consequences for intergroup relations. It is associated with intergroup hostility and prejudice (Golec de Zavala et al., 2019; Lyons et al., 2010), conspiratorial thinking (Cichocka et al., 2016; Golec de Zavala \& Federico, 2018), and populist voting (Federico \& Golec de Zavala, 2018). Although the consequences of collective narcissism are well established, its predictors are less so. Research has focused on individual-level predictors of collective narcissism such as personal control (Cichocka et al., 2018), individual narcissism (Golec de Zavala, 2018), and low individual self-esteem (Golec de Zavala et al., 2020). However, no studies have examined intergrouplevel predictors of collective narcissism. We propose that perceived intergroup threat predicts collective narcissism, given that collective narcissism is associated with hypersensitivity to threats to the ingroup image (Golec de Zavala et al., 2016). This proposal is consistent with evidence indicating that collective narcissism is linked to perceptions of ingroup disadvantage (Golec de Zavala et al., 2009) and mediates the effect of perceived disadvantage on populist attitudes (Marchlewska et al., 2018).

We extend the rejection identification model's proposal that intergroup threat stemming from rejection and discrimination strengthens positive identification with the threatened ingroup (Branscombe, Schmitt, \& Harvey, 1999) in two ways. First, we differentiate between two forms of intergroup threat: integrated threat (Stephan et al., 2002; Stephan et al., 2009) and distinctiveness threat (Branscombe, Schmitt, \& Harvey, 1999; Jetten \& Spears, 2003; Vignoles et al., 2000), asking whether they predict similarly negative intergroup outcomes. Second, we differentiate between two forms of (national) ingroup positivity: collective narcissism (Golec de Zavala et al., 2009) and ingroup satisfaction (Leach et al., 2008), proposing that only collective narcissism, but not ingroup satisfaction, mediates the positive relations between intergroup threat and hostile intergroup relations.

\section{Integrated and Distinctiveness Threats}

Intergroup threat arises when an individual perceives that another group can harm their ingroup. 
According to integrated threat theory (currently known as intergroup threat theory; Stephan et al., 2009), intergroup threats can be realistic (i.e., targeting the group's power, resources, and general welfare) or symbolic (i.e., targeting the group's religion, values, norms, ideology, or worldview). Intergroup threats have been linked to several negative intergroup outcomes - cognitive, emotional, and behavioral (Riek et al., 2006; Stephan et al., 2009). For example, both realistic and symbolic threats have been linked to support for persecution of Muslim immigrants among non-Muslim Americans (Obaidi et al., 2018), and to support for violent behavioral intentions among British and Norwegian Muslims (Tahir et al., 2019). Besides behavioral outcomes, perceived threat also triggers various negative emotional responses to outgroups such as fear and anger (Cottrell \& Neuberg, 2005) and even schadenfreude (i.e., pleasure in response to outgroup misfortune; Chang et al., 2016), as well as negative cognitive responses such as increased ingroup versus outgroup categorization and stereotyping (Chang et al., 2016; Riek et al., 2006).

Besides integrated threat (i.e., realistic and symbolic), there are other threats to social identity, such as distinctiveness threat (Branscombe, Ellemers, et al., 1999). The relevance of distinctiveness as a guiding principle of identity processes is well established in research traditions inspired by social identity theory (Tajfel \& Turner, 1979) and identity process theory (Breakwell, 1987; Vignoles et al., 2000). Distinctiveness has been conceptualized mainly in terms of similarity/dissimilarity (Jetten et al., 2001), but it can also be achieved in terms of position or separateness (Vignoles et al., 2000). We conceptualize distinctiveness based on similarity with a relevant outgroup, defining it as "the perceived difference or dissimilarity between one's own group and another group on a relevant dimension" Jetten et al., 2001, p. 621). When distinctiveness needs are threatened by similarity with relevant outgroups, individuals are motivated to restore the ingroup's distinctiveness by strengthening intergroup differentiation. Such increased intergroup differentiation is manifested in behavioral outcomes like greater reward allocations to the ingroup than the outgroup (Jetten et al., 2004).

Yet, perceived intergroup threats can also increase ingroup positivity. In particular, they increase group cohesion (Stephan et al., 2009) and group identification (Branscombe, Schmitt, \& Harvey, 1999). Thus, there are reasons to expect that they should increase ingroup satisfaction and collective narcissism. Although collective narcissism is not conceptualized as general ingroup identification but rather as a specific belief about the unrecognized greatness of the ingroup, it correlates with specific aspects of ingroup identification (Golec de Zavala et al., 2019; Golec de Zavala et al., 2020). In particular, it is associated with ingroup satisfaction, a form of self-investment in the group that reflects its positive evaluation (also called private collective self-esteem; Crocker \& Luhtanen, 1990; Leach et al., 2008). Collective narcissism and ingroup satisfaction refer to alternative and positive beliefs or evaluations of one's group (Golec de Zavala et al., 2020). Building on empirical findings showing that threats to one's ingroup strengthen ingroup identification (Branscombe, Schmitt, \& Harvey, 1999; Schmid \& Muldoon, 2015), we propose that both integrated and distinctiveness threats are positively related to collective narcissism and ingroup satisfaction.

\section{Collective Narcissism and Ingroup Satisfaction: Different Forms of Ingroup Positivity}

Collective narcissism and ingroup satisfaction are distinct forms of positive beliefs about the ingroup. Both pertain to the self-investment dimension of ingroup identification, but they have different associations with its remaining components. Ingroup satisfaction is positively correlated with other aspects of self-investment: ingroup centrality (i.e., the importance and salience of ingroup membership) and solidarity with ingroup members (Leach et al., 2008). Collective narcissism is positively associated with ingroup satisfaction and ingroup centrality (Golec de Zavala et al., 2019), but it is not associated with 
solidarity with ingroup members. In fact, collective narcissism predicts disloyalty toward ingroup members (Marchlewska et al., 2020) and lack of solidarity with ingroup members during the COVID-19 pandemic (Federico et al., 2020). In addition, ingroup satisfaction is positively associated with the self-definition dimension of ingroup identification (i.e., defined by self-stereotyping and perceived ingroup homogeneity; Leach et al., 2008). However, collective narcissism is only weakly related to this dimension (Golec de Zavala et al., 2019; Jaworska, 2016; Marchlewska et al., 2020).

In the current research, we focused on the comparison of collective narcissism and ingroup satisfaction, as differentiating the two "is the most theoretically important for understanding of collective narcissism, as both variables pertain to the role the positive evaluation of the ingroup plays for the self" (Golec de Zavala et al., 2019, p. 45). Although collective narcissism and ingroup satisfaction overlap positively, they make strikingly different predictions for intergroup relations, especially when their common overlap is partialled out. Collective narcissism with ingroup satisfaction partialled out can be interpreted as group-based entitlement without the comfort of belonging to a valued ingroup. Its focus is on the demand for privileged treatment and a concern about loss of the ingroup's external recognition (Cichocka, 2016; Golec de Zavala, 2018; Golec de Zavala et al., 2019). Collective narcissism is associated with prejudice, intergroup hostility, revengefulness, and retaliatory aggression, as well as conspiracy beliefs about malevolent intentions of others (regardless of whether its overlap with ingroup satisfaction is partialled out; Golec de Zavala et al., 2019). In contrast, ingroup satisfaction with collective narcissism partialled out can be interpreted as secure ingroup positivity, independently of the need to be recognized and admired by others. Although some studies found that, when controlling for collective narcissism, ingroup satisfaction was negatively related to prejudice and hostility (Golec de Zavala et al., 2013, Studies 1-4; Golec de Zavala et al., 2020, Studies 3 and 4), others showed no significant, unique association between ingroup satisfaction and intergroup hostility (Cichocka et al., 2016; Dyduch-Hazar et al., 2019; Golec de Zavala et al., 2020, Studies 5-7). Given that previous findings regarding collective narcissism have been consistent, we hypothesized that collective narcissism would mediate the relation between intergroup threat and hostility. However, given that prior findings regarding ingroup satisfaction haven been inconsistent, we exploratorily examined its potential mediating role.

\section{Overview}

In two studies conducted in four EU countries (Germany, Greece, Portugal, the United Kingdom [UK]), we hypothesized that integrated threat (Study 1) and distinctiveness threat (Study 2) would positively predict collective narcissism and ingroup satisfaction (H1). We further hypothesized that collective narcissism would mediate the association between intergroup threat and intergroup hostility toward the threatening outgroups (H2).

In both studies, we assessed intergroup hostility as negative emotions and hostile behavioral intentions toward the threatening outgroups. We conducted pilot tests to determine the relevant outgroups for comparison in each country (see Table 1 for selected groups for each type of threat used in Studies 1 and 2). ${ }^{1}$ We obtained ethical approval for all studies via the Ethics Committee of the Instituto Universitário de Lisboa (ISCTE-IUL, CIS-IUL).

\section{Study 1}

In Study 1, we focused on integrated threat. We examined, in particular, whether it predicts higher collective narcissism and ingroup satisfaction (H1). We further tested whether collective narcissism would mediate the link between integrated threat and intergroup hostility toward the threatening outgroups (H2). We also explored the mediating role of ingroup satisfaction. 
Table 1. Target groups and reliabilities (Cronbach's $\alpha$ ) of measures per country: Studies 1 and 2

\begin{tabular}{|c|c|c|c|c|c|c|c|c|}
\hline & \multicolumn{2}{|l|}{ Germany } & \multicolumn{2}{|l|}{ Greece } & \multicolumn{2}{|l|}{ Portugal } & \multicolumn{2}{|l|}{ UK } \\
\hline & Target & $\alpha$ & Target & $\alpha$ & Target & $\alpha$ & Target & $\alpha$ \\
\hline \multicolumn{9}{|l|}{ Study 1} \\
\hline Realistic threat & Swedes & .94 & Germans & .92 & Germans & .90 & Germans & .92 \\
\hline Symbolic threat & Poles & .86 & Germans & .88 & Germans & .80 & Romanians & .92 \\
\hline Collective narcissism & & .88 & & .88 & & .76 & & .88 \\
\hline $\begin{array}{l}\text { National identity } \\
\text { satisfaction }\end{array}$ & & .92 & & .90 & & .90 & & .94 \\
\hline Negative emotions & Same as threat & .86 & Same as threat & .76 & Same as threat & .79 & Same as threat & .87 \\
\hline $\begin{array}{l}\text { Hostile behavioral } \\
\text { intentions }\end{array}$ & Same as threat & .97 & Same as threat & .92 & Same as threat & .92 & Same as threat & .94 \\
\hline \multicolumn{9}{|l|}{ Study 2} \\
\hline Distinctiveness threat & Austrians & .87 & Italians & .86 & Spaniards & .85 & the Irish & .87 \\
\hline Collective narcissism & & .88 & & .89 & & .80 & & .89 \\
\hline $\begin{array}{l}\text { National identity } \\
\text { satisfaction }\end{array}$ & & .92 & & .90 & & .91 & & .95 \\
\hline Negative emotions & Same as threat & .95 & Same as threat & .74 & Same as threat & .87 & Same as threat & .85 \\
\hline $\begin{array}{l}\text { Hostile behavioral } \\
\text { intentions }\end{array}$ & Same as threat & .97 & Same as threat & .84 & Same as threat & .87 & Same as threat & .94 \\
\hline
\end{tabular}

\section{Method}

Participants. In each country, we targeted a sample size of approximately 250 (Schönbrodt \& Perugini, 2013), although we were constrained by the available research budget. We excluded from the analyses participants who reported other citizenship than that of the country of interest (six in Germany, four in Greece, two in Portugal). In Germany, the sample consisted of 224 participants (92 women) with a mean age of 38.20 years $(S D=12.46)$. In Greece, the sample consisted of 243 participants (161 women) with a mean age of 38.38 years $(S D=13.23)$. In Portugal, the sample consisted of 236 participants (154 women) with a mean age of 29.88 years (SD $=10.72)$. Finally, in the UK, the sample consisted of 233 participants (144 women) with a mean age of 36.62 years $(S D=11.35)$. The overall sample comprised 936 participants.

Procedure. Participant recruitment differed somewhat across countries. In Germany, we recruited participants via the Clickworker online platform, and paid them $€ 1.95$. In Greece, we recruited participants via academic mailing lists and social networks. In Portugal, we disseminated the study through academic informal networks and on social media; here, participants completed an online survey in exchange for a chance to win one of three $€ 25.00$ vouchers in a lottery. Lastly, in the UK, we recruited participants via the Prolific Academic online platform, and paid them $f 1.75 .^{2}$

In all countries, we collected the data online via Qualtrics. Following consent, participants responded to one, randomly presented, measure of integrated threat (i.e., realistic or symbolic). The targets for realistic and symbolic threats differed (see Table 1). We determined these targets based on pilot testing. In addition, we chose to present randomly either the realistic or symbolic threat items to minimize response biases. Presenting each integrated threat measure on a within-subjects basis would require participants to complete the corresponding outcome measures (i.e., negative emotions, intergroup hostile behavioral intentions) for more than one target outgroup, given that different threats were elicited by different groups. This practice would extend the length of the survey and the time to 
complete it, possibly leading to fatigue and malaise, which have been linked to measurement error (Egleston et al., 2011), as well as low motivation and satisficing, which have been linked to arbitrary responding (Krosnick \& Presser, 2010).

Other measures (collective narcissism, ingroup satisfaction $^{3}$ ) followed in a separate random order for each participant. Negative emotions, intergroup hostility, and demographics were presented last. Debriefing concluded the survey.

Measures. Response options ranged from 1 to 7 for all measures (for integrated threat, collective narcissism, and ingroup satisfaction: 1 = strongly disagree, 7 = strongly agree; for negative emotions and hostile behavior intentions: $1=$ not at all, 7 $=$ extremely). We administered all measures in the relevant national language and, except for the UK, we translated and back translated them. All variables were created by mean scoring across individual items for each scale. We report scale reliabilities for the four countries in Table 1, and means and standard deviations in Table 2.

Integrated threat. We measured integrated threat (i.e., realistic and symbolic) with a scale adapted from Stephan et al. (2002). A sample item for realistic threat is: "[national outgroup] hold too many positions of power and responsibility in the European Union." A sample item for symbolic threat is: "[national ingroup] and [national outgroup] have very different values." We chose to combine realistic and symbolic threat scales (i.e., integrated threat) given that they yielded very similar correlations with all variables and, when treated separately, the results of the predicted mediation models were virtually identical (see bivariate correlations and parallel mediation models separately for each threat in the supplemental material). Combining realistic and symbolic threats is common practice in the literature (Costello \& Hodson, 2011), as the two types of threat predict similar outcomes (Aberson, 2019).

Collective narcissism. We measured collective narcissism with a five-item scale adapted from Golec de Zavala et al. (2009). A sample item is: "The [national ingroup] deserve special treatment."
Ingroup satisfaction. We used four items from Leach et al. (2008) to measure ingroup satisfaction. A sample item is: "I'm glad to be [national ingroup]."

Negative emotions. We measured negative emotions with a scale adapted from Cottrell and Neuberg (2005). The scale asks for the extent to which participants felt angry, disgusted, fearful, pity, envious, guilty, and concerned/worried when thinking of the target outgroup.

Hostile behavioral intentions. We used a scale adapted from Mackie et al. (2000) to measure hostile behavioral intentions. The scale asks for the extent to which participants wanted to confront, oppose, hurt, offend, injure, intimidate, humiliate, avoid, ignore, or have nothing to do with them when thinking of or interacting with the target outgroup. The target matched the one for integrated threat.

Demographics. Participants completed standard demographic questions (e.g., sex, age, education, citizenship), as well as an ethnic/national categorization measure: "Which group do you most identify with? (check only one)." Response options included relevant majorities and minorities in each country.

\section{Results}

We report bivariate correlations in Table 2 . In order to test the hypotheses that integrated threat predicts both forms of ingroup positivity, but only collective narcissism mediates the link between integrated threat and intergroup hostility, we specified an unconstrained (i.e., all paths vary freely between countries) parallel mediation model with one predictor (integrated threat), two parallel mediators (collective narcissism, ingroup satisfaction), and two outcome variables (negative emotions, hostile behavioral intentions) for the overall sample. This model was saturated (i.e., with zero degrees of freedom), and thus we do not report standard global fit indices used in structural equation modelling. We conducted the analyses 
Table 2. Means, standard deviations, and correlations among Study 1 variables for overall sample

\begin{tabular}{|c|c|c|c|c|c|c|c|}
\hline & & Mean & $S D$ & 1 & 2 & 3 & 4 \\
\hline 1 & Integrated threat & 3.95 & 1.21 & & & & \\
\hline 2 & Collective narcissism & 3.53 & 1.32 & $.56^{*}$ & & & \\
\hline 3 & National identity satisfaction & 5.27 & 1.32 & $.40^{*}$ & $.56^{*}$ & & \\
\hline 4 & Negative emotions & 2.05 & 1.08 & $.45^{*}$ & $.36^{*}$ & $.13^{*}$ & \\
\hline 5 & Hostile behavioral intentions & 1.73 & 1.14 & $.46^{*}$ & $.41 *$ & $.16^{*}$ & $.59 *$ \\
\hline
\end{tabular}

Note. Significance level: ${ }^{*} p<.001 .933 \leqslant n \leqslant 936$.

using the lavaan package (Version 0.6-3) for $\mathrm{R}$ (Rosseel, 2012).

To ensure that our model was relevant for all four countries, we then tested it as a multigroup model with all paths constrained to equality across countries. To provide a test of the indirect effects, we used bootstrapping with 10,000 samples and 95\% percentile intervals (Ryu \& Cheong, 2017). We assessed this model's fit with the data $(\mathrm{CFI}=.96, \mathrm{TLI}=.94$, robust $\mathrm{RMSEA}=.09$, $90 \%$ CI $[0.07,0.123], p_{\text {close }}=.001$, SRMR $=$ .102). The confidence intervals for RMSEA did not include .05 , and the $p$ value of close fit was significant, indicating that the model was not close-fitting (Kenny et al., 2015) possibly because some paths might differ between countries (Byrne, 2001).

To address the issue of between-country path differences, we conducted a series of Wald tests evaluating structural equivalence of the model across countries. These analyses revealed that two paths were different in Greece relative to other countries: the path from integrated threat to collective narcissism and the path from integrated threat to ingroup satisfaction. The direct path from integrated threat to negative emotions was also different for Germany and Greece relative to other countries (see full description of Wald tests and sequential constraints in the supplemental material). We therefore retested our multigroup model with these three paths allowed to vary, and constrained all remaining paths to equality across all countries. This model showed a significantly better fit than the previous model with all paths constrained, $\Delta \chi(3)=37.66, p<.001 ; \mathrm{CFI}=.99$, TLI $=.97$, RMSEA $=.06,90 \%$ CI $[0.03,0.09]$, $p_{\text {close }}=.22$, SRMR $=.06$, with the
RMSEA confidence intervals including .05 and a nonsignificant $p$ value. We concluded that, although the tested associations between variables held for the four countries, the strength of the effects of integrated threat varied between countries on the specific paths that we set free in this model.

We report path coefficients for this model in Figure 1, and indirect and total effects in Table 3. As hypothesized, integrated threat was positively related to collective narcissism and ingroup satisfaction in all countries (H1), and these effects were stronger in Greece. Collective narcissism was positively related to both hostile behavioral intentions and negative emotions. In addition, ingroup satisfaction showed a significant negative association with both outcome variables, suggesting the existence of a suppressor effect between the two mediators. We tested the suppression effect of ingroup satisfaction on the links between collective narcissism and hostile behavioral intentions, and between collective narcissism and negative emotions (MacKinnon et al., 2000). We found the expected pattern, that is, direct and indirect effects showed opposite signs: (a) for direct effects, $B_{\text {hostile behavior }}=0.41, p<$ .001 , and $\mathrm{B}_{\text {negative emotions }}=0.34, p<.001$; (b) for indirect effects, $\mathrm{B}_{\text {hostile behavior }}=-0.05,95 \% \mathrm{CI}$ $[-0.09,-0.02]$, and $\mathrm{B}_{\text {negative emotions }}=-0.05,95 \%$ CI $[-0.08,-0.02]$. All direct and total effects of integrated threat on negative emotions and intergroup hostility were significant across the four countries (see Table 3).

As hypothesized (H2), the indirect effects of integrated threat on negative emotions and hostile behavioral intentions via collective narcissism were significant and positive. The indirect effects of 
Figure 1. Constrained path model in Study 1 with paths from integrated threat to both mediators allowed to vary for Greece, and with the path from integrated threat to negative emotions allowed to vary between the country pairs Germany-Greece and Portugal-UK, and set to equality within the country pairs Germany-Greece and Portugal-UK.

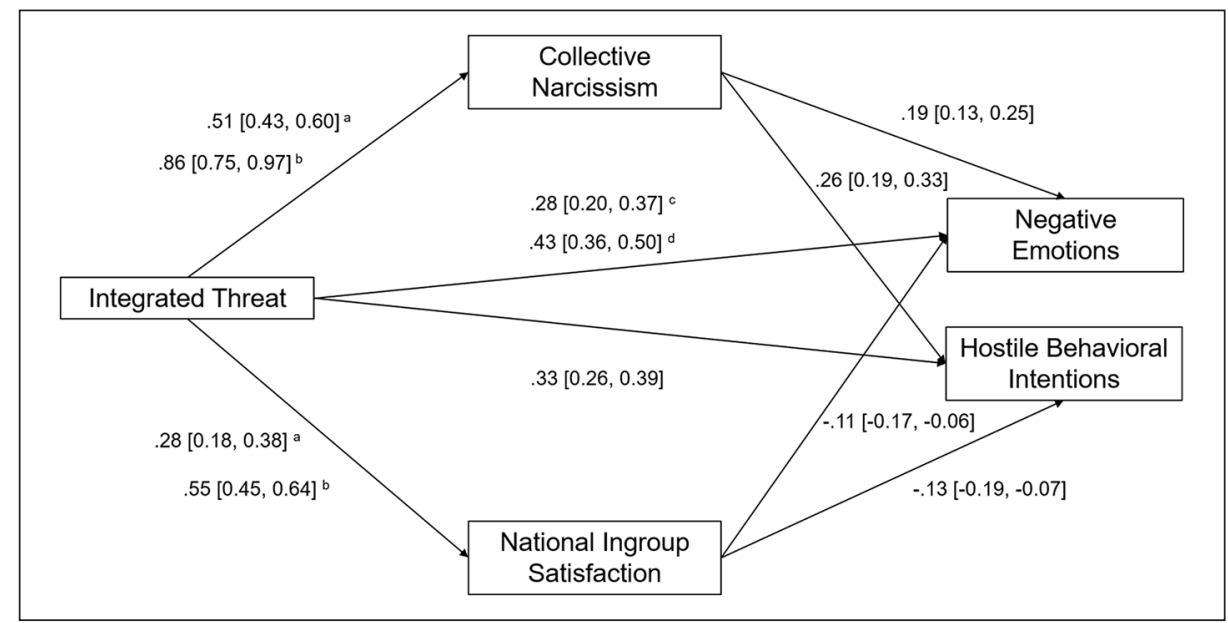

Note. Unstandardized regression coefficients (and 95\% percentile bootstrap intervals) are reported. Coefficients between independent variables and dependent variables are direct effects in the presence of mediators.

${ }^{a}$ Effect in Germany, Portugal, and the UK; beffect in Greece; 'effect in Portugal and the UK; deffect in Germany and Greece.

integrated threat on negative emotions and hostile behavioral intentions were also significant via ingroup satisfaction, but in the opposite direction: integrated threat was negatively related to both intergroup outcomes via ingroup satisfaction. Given that the indirect effect via ingroup satisfaction was not hypothesized, we additionally carried out a contrast analysis by subtracting the absolute value of the indirect effect via ingroup satisfaction from the value of the indirect effect via collective narcissism for both outcomes separately, and by bootstrapping the result (Preacher \& Hayes, 2008). These contrasts were positive and significant (see Table 3), suggesting that the indirect effect via collective narcissism was significantly larger than the indirect effect via ingroup satisfaction for both outcomes and in all countries.

\section{Discussion}

The Study 1 results were in line with our hypothesis (H1) that intergroup threat is associated with two forms of ingroup positivity: collective narcissism and ingroup satisfaction. Consistent with previous findings linking integrated threat (i.e., realistic and symbolic) to increased ingroup identification (Schmid \& Muldoon, 2015), integrated threat positively predicted two aspects of ingroup identification: collective narcissism and ingroup satisfaction. Importantly, these two forms of ingroup positivity had differential and unique associations with intergroup relations. Collective narcissism was positively related to hostile behavior intentions and negative emotions. Supportive of our hypothesis (H2), it mediated the relation between perceived integrated threat and negative intergroup relations. In contrast, ingroup satisfaction, when controlling for collective narcissism, was negatively associated with these outcomes. It also mediated the associations of integrated threat with hostile behavioral intentions and negative emotions, but this took the form of inconsistent mediation or suppression (Paulhus et al., 2004). Although we did not predict ingroup satisfaction to mediate the association of perceived threat and negative intergroup outcomes, this finding is in line with previous results showing that ingroup satisfaction, after controlling for 


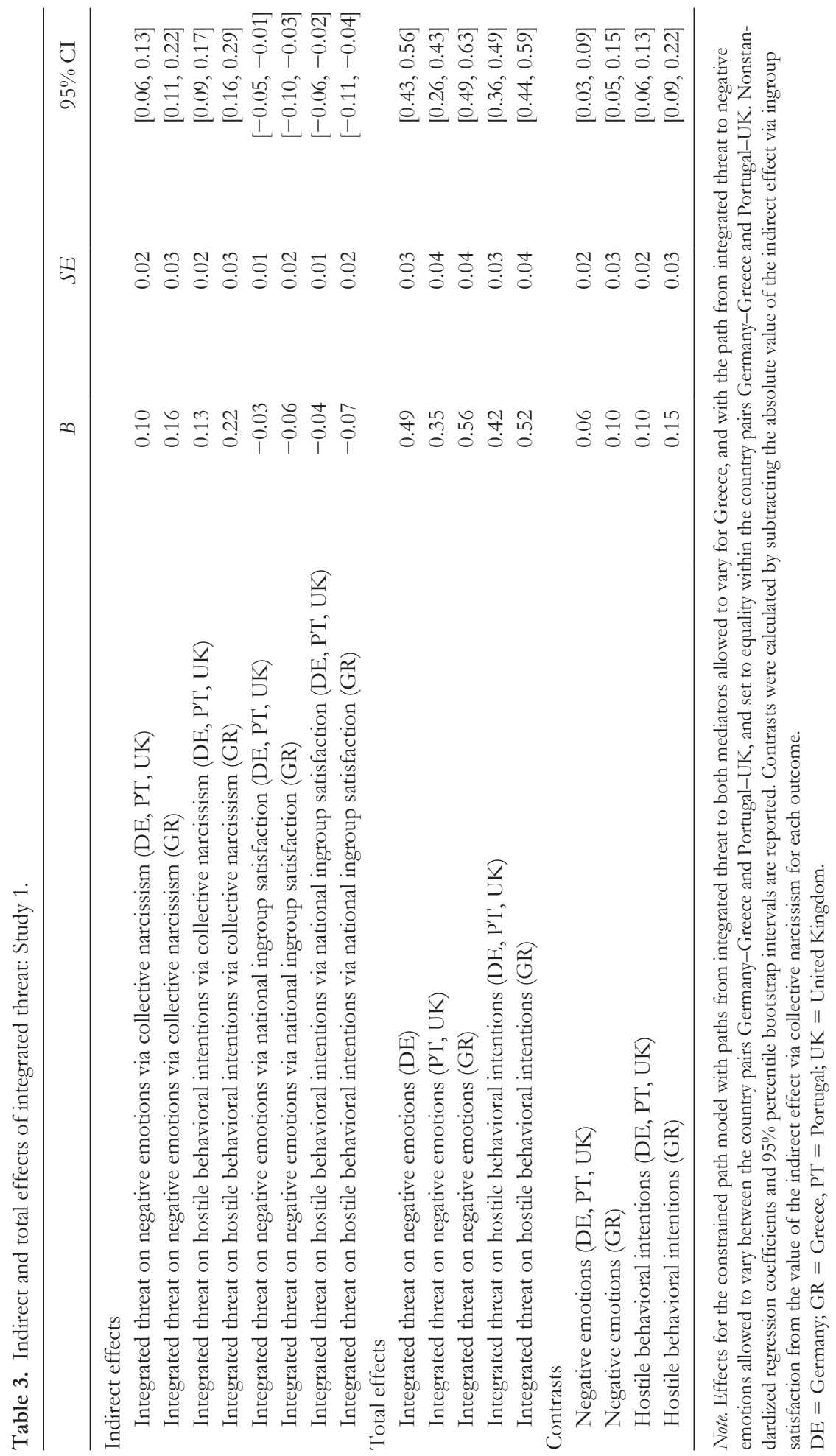


collective narcissism, is related to less outgroup negativity (Golec de Zavala et al., 2013; Golec de Zavala et al., 2020, Studies 3 and 4), and that the unique associations between collective narcissism and ingroup satisfaction with intergroup hostility are often opposite (Golec de Zavala et al., 2019). However, other studies showed no significant associations between ingroup satisfaction and intergroup outcomes (Cichocka et al., 2016; Dyduch-Hazar et al., 2019; Golec de Zavala et al., 2020, Studies 5-7). Different measures have been used to assess outgroup negativity, ranging from attitudinal indices like social distance, emotions, and feelings of warmth, to behavioral ones like voodoo doll use (in the context of symbolic aggression). Generally, ingroup satisfaction is significantly negatively related to negative intergroup outcomes when attitudinal measures, rather than behavioral ones, are used (Golec de Zavala et al., 2020). Thus, this effect may be less stable than the one found for collective narcissism, and may depend on how the outcome is measured.

The multigroup analyses testing the equality of the proposed relations among integrated threat, ingroup positivity, and intergroup outcomes across the four countries revealed some unpredicted differences. The associations between integrated threat and both forms of ingroup positivity were stronger in Greece than in Germany, Portugal, and the UK, and the direct link between integrated threat and negative emotions toward the outgroup was particularly strong in Germany and Greece. Although not hypothesized, the differences in the relation between perceived threat and both ingroup satisfaction and collective narcissism can be considered in the context of the EU 2009 economic crisis. The economic and social consequences of the resulting austerity programs were particularly drastic in Greece (e.g., growing poverty and unemployment, decline in health indicators, rise of antiimmigrant attitudes; Petropoulos \& Tsobanoglou, 2014), and are reverberating to this day. Several of these indicators (e.g., increased unemployment, decrease GDP) qualify as sources of mate$\mathrm{rial} /$ realistic threat. Accordingly, the impact of perceived threat on both forms of ingroup positivity could have been exacerbated in this national context, given the salience of real threat indicators. Research comparing national identification in several EU countries before (2005) and during the crisis (2010) showed that citizens of countries most affected by the economic crisis, including Greece, increased their identification with their nation, while decreasing their identification with the EU (Polyakova \& Fligstein, 2016).

Also, Germany played a pivotal role in economic bailouts to diffuse the crisis (Schild, 2020; Schoeller, 2017). The crisis and bailouts were often presented negatively in German public and media discourse, creating a narrative of the "corrupt and lazy Greeks in comparison to the hardworking Germans" (Bickes et al., 2014, p. 426), and even demanding Greece's exit from the EU. Similarly, Germany was blamed for the negative impact of austerity programs by political parties in Greece (Vasilopoulou et al., 2014). Thus, the impact of integrated threat on negative emotions may have been exacerbated in both countries. Future research would need to replicate and explicate these findings.

\section{Study 2}

In Study 2 we tested the same hypotheses as in Study 1, but we focused on a different type of intergroup threat. Specifically, we expected that distinctiveness threat would positively predict collective narcissism and ingroup satisfaction (H1), and that collective narcissism would mediate the relation between distinctiveness threat and intergroup hostility, assessed as negative intergroup emotions and hostile behavioral intentions (H2). As in Study 1, we further explored the mediating role of ingroup satisfaction.

\section{Method}

Participants. Although we did not anticipate country-level differences, we wanted to ensure a sufficiently large sample size per country to be able to conduct country-level analyses, if needed. Study 1 yielded relatively large effect sizes for the focal constructs: .51 in Germany, Portugal, and the UK, and .86 in Greece, for the path between integrated 
Table 4. Means, standard deviations, and Pearson's correlations between Study 2 variables for overall sample

\begin{tabular}{llcccccc}
\hline & Mean & $S D$ & 1 & 2 & 3 & 4 \\
\hline 1 & Distinctiveness threat & 3.93 & 1.53 & & & \\
2 & Collective narcissism & 3.56 & 1.33 & $.25^{*}$ & & \\
3 & National identity satisfaction & 5.40 & 1.24 & $.17^{*}$ & $.59^{*}$ & \\
4 & Negative emotions & 1.49 & 0.82 & $.12^{*}$ & $.18^{*}$ & -.01 & \\
5 & Hostile behavioral intentions & 1.33 & 0.71 & $.18^{*}$ & $.23^{*}$ & .02 & $.58^{*}$ \\
\hline
\end{tabular}

Note. Significance level: ${ }^{*} p<.001 .480 \leqslant n \leqslant 484$.

threat and collective narcissism (see Figure 1). Data simulation studies suggest that, with a regression coefficient within the range of .39 to .59 , a sample of 100 or slightly bigger suffices even in the case of more complex models (e.g., complex moderated mediation models; Preacher et al., 2007). Therefore, we aimed for samples between 100 and 150 participants per country, with budget availability being a constraining factor. We excluded from the analyses participants who reported other citizenship than that of the country of interest (six in Germany, two in Greece, one in Portugal). In Germany, the sample comprised 111 participants (51 women) with a mean age of 37.27 years $(S D=$ 11.04). In Greece, the sample comprised 131 participants (99 women) with a mean age of 37.41 years $(S D=13.05)$. In Portugal, the sample comprised 122 participants (83 women) with a mean age of 31.3 years $(S D=12.99)$. In the UK, the sample comprised 120 participants (77 women) with a mean age of 37.73 years $(S D=12.85)$. The overall sample consisted of 484 participants.

Procedure. Participant recruitment and data collection were conducted as in Study 1. The targets for distinctiveness threat differed for each country (see Table 1), and we determined them on the basis of the pilot testing reported in Study 1 (see Endnote 1 for detailed description). We presented the measures in the same order as in Study 1.

Measures. Response options for all measures ranged from 1 to 7, as in Study 1. We administered measures in relevant national languages, and we translated and back translated these measures for the German, Greek, and Portuguese samples.
We created all variables by mean scoring across individual items for each scale. We report scale reliabilities for the four countries in Table 1, and means and standard deviations in Table 4.

Distinctiveness threat. We measured distinctiveness threat with a four-item scale adapted from Schmid et al. (2009). A sample item is: "It annoys me when others don't see the important differences between the [national ingroup] and the [national outgroup]."

Collective narcissism and ingroup satisfaction. We measured collective narcissism and ingroup satisfaction with the same scales as in Study 1.

Negative emotions and hostile behavioral intentions. We measured negative emotions and hostile behavioral intentions with the same scales as in Study 1. The target for these measures matched the one for threat.

Demographics. Participants responded to the same demographic questions as in Study 1.

\section{Results}

We report bivariate correlations in Table 4. We conducted the analyses using the lavaan package (Version 0.6-3) for R (Rosseel, 2012). Similar to Study 1, we specified an unconstrained parallel mediation model with one predictor (distinctiveness threat), two mediators (collective narcissism, ingroup satisfaction), and two outcomes (negative emotions, hostile behavioral intentions) for the overall sample. This model was saturated (i.e., 
Figure 2. Path model for the overall sample in Study 2.

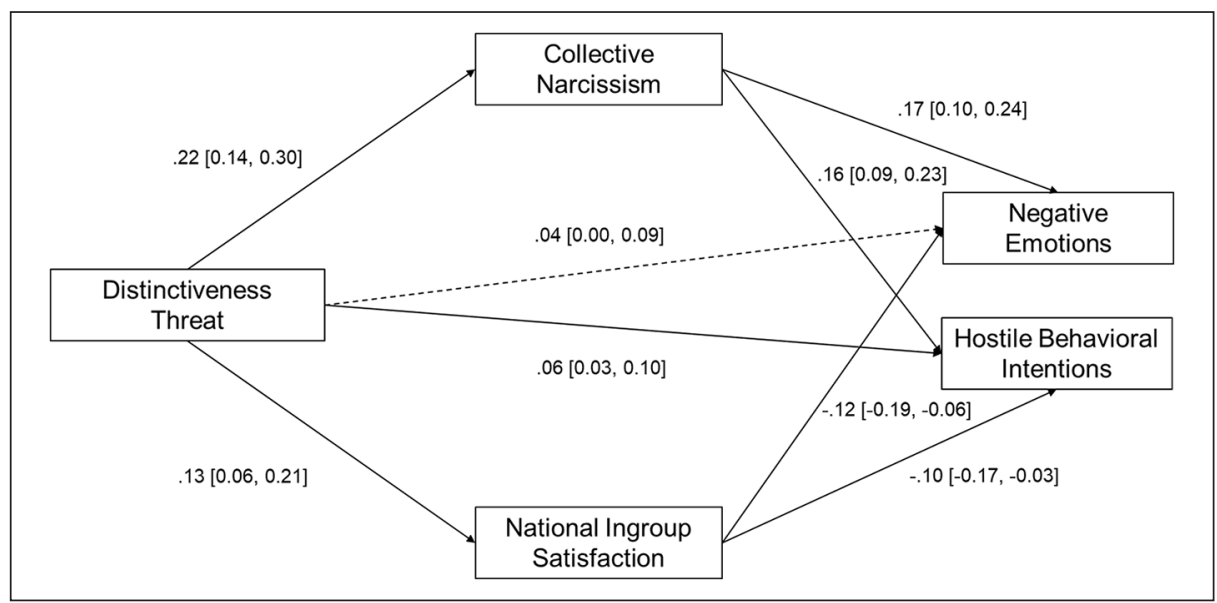

Note. Unstandardized regression coefficients (and 95\% percentile bootstrap intervals) are reported. Coefficients between independent variables and dependent variables are direct effects in the presence of mediators.

with zero degrees of freedom), and thus we do not report standard global fit indices used in structural equation modelling. We then tested the same model as a multigroup model with all paths constrained to equality across the four countries. Again, we used bootstrap with 10,000 samples and $95 \%$ percentile intervals. Fit indices of the constrained model were acceptable (CFI $=.96$, TLI $=.94$, RMSEA $=.08,90 \%$ CI $[0.04,0.12]$, $p_{\text {close }}=.12$, SRMR $\left.=.07\right)$, and the confidence interval for RMSEA including .05 and a nonsignificant $p$ value suggested a close fit with the data (Kenny et al., 2015). We therefore concluded that there were no relevant differences between countries. We report the results for the overall sample in Figure 2 (path coefficients) and in Table 5 (indirect and total effects).

In line with $\mathrm{H} 1$, distinctiveness threat was positively related to collective narcissism and ingroup satisfaction. Collective narcissism was positively related to negative emotions and hostile behavioral intentions. In addition, like in Study 1, ingroup satisfaction, after controlling for collective narcissism, showed a negative association with both outcomes, suggesting the existence of a suppressor effect between the two mediators (see Table 5). As in Study 1, we tested the suppression effect of ingroup satisfaction on the links between collective narcissism and hostile behavioral intentions, and between collective narcissism and negative emotions (MacKinnon et al., 2000). We obtained the expected pattern: (a) for direct effects, $\mathrm{B}_{\text {hostile behavior }}$ $=0.17, p<.001$, and $\mathrm{B}_{\text {negative emotions }}=0.18, p<$ .001 ; (b) for indirect effects, $\mathrm{B}_{\text {hostile behavior }}=-0.05$, $95 \%$ CI $[-0.09,-0.02]$, and $\mathrm{B}_{\text {negative emotions }}=$ $-0.07,95 \%$ CI $[-0.11,-0.03]$. Moreover, all total effects of distinctiveness threat on negative emotions and intergroup hostility were significant.

As hypothesized, the positive relation between distinctiveness threat and both intergroup outcomes occurred via collective narcissism (H2). Not predicted, but replicating the findings of Study 1, was the significant negative indirect effect of distinctiveness threat on negative emotions and hostile behavior intentions via ingroup satisfaction. Again, we carried out a contrast analysis by subtracting the absolute value of the indirect effect via ingroup satisfaction from the value of the indirect effect via collective narcissism for both outcomes separately, and by bootstrapping the result (Preacher \& Hayes, 2008). This analysis revealed a positive and significant contrast between both effects for both outcomes, suggesting that the effect via collective narcissism was significantly larger, as in Study 1. As to direct associations, 
Table 5. Indirect and total effects of distinctiveness threat: Study 2.

\begin{tabular}{lccc}
\hline & $B$ & $S E$ & $95 \% \mathrm{CI}$ \\
\hline Indirect effects & & & \\
$\quad$ Distinctiveness threat on negative emotions via collective narcissism & 0.04 & 0.01 & {$[0.02,0.06]$} \\
Distinctiveness threat on hostile behavioral intentions via collective narcissism & 0.03 & 0.01 & {$[0.02,0.06]$} \\
Distinctiveness threat on negative emotions via national ingroup satisfaction & -0.02 & 0.01 & {$[-0.03,-0.01]$} \\
$\quad \begin{array}{l}\text { Distinctiveness threat on hostile behavioral intentions via national ingroup } \\
\text { satisfaction }\end{array}$ & -0.01 & 0.01 & {$[-0.03,-0.003]$} \\
Total effects & & & \\
$\quad \begin{array}{l}\text { Distinctiveness threat on negative emotions } \\
\text { Distinctiveness threat on hostile behavioral intentions }\end{array}$ & 0.07 & 0.02 & {$[0.02,0.11]$} \\
Contrasts & 0.08 & 0.02 & {$[0.05,0.13]$} \\
$\quad$ Negative emotions & & & \\
$\quad$ Hostile behavioral intentions & 0.02 & 0.02 & {$[0.01,0.04]$} \\
\hline
\end{tabular}

Note. Reported effects refer to the path model for the overall sample. Unstandardized regression coefficients and $95 \%$ percentile bootstrap intervals are reported. Contrasts were calculated by subtracting the absolute value of the indirect effect via ingroup satisfaction from the value of the indirect effect via collective narcissism for each outcome.

distinctiveness threat was positively related to hostile behavioral intentions, but its association with negative emotions was not significant. This, together with a significant total effect, suggest that the association between distinctiveness threat and negative emotions is explained by an increase in collective narcissism and in ingroup satisfaction.

\section{Discussion}

Study 2 provided further support for our proposal that intergroup threat is a key predictor of different forms of ingroup positivity, and extended it to a less studied form of threat, distinctiveness threat. Mirroring the Study 1 findings with reference to integrated threat, distinctiveness threat was positively associated with collective narcissism and ingroup satisfaction. Consistent with previous research (Golec de Zavala et al., 2019), and replicating the Study 1 findings, these two forms of ingroup positivity were differentially linked to intergroup outcomes. Specifically, whereas collective narcissism was positively associated with negative emotions and hostile behavioral intentions toward the threatening outgroup, ingroup satisfaction, when controlling for collective narcissism, was again negatively related to these outcome variables.
Unlike in Study 1, in Study 2 we obtained no between-country differences.

\section{General Discussion}

Taking an intergroup approach to collective narcissism, we illustrated for the first time that different types of intergroup threat, in particular integrated and distinctiveness threat, predict different forms of national ingroup positivity, in particular national collective narcissism and national ingroup satisfaction. The findings were consistent across two studies conducted in four EU countries. Integrated and distinctiveness threats positively predicted collective narcissism and ingroup satisfaction in all countries. These findings are in accord with both the rejection identification model (Branscombe, Schmitt, \& Harvey, 1999) and the threat identification model (Schmid \& Muldoon, 2015), which hold that threats to one's identity (i.e., discrimination and integrated threat) increase identification with the ingroup. At the same time, our findings specify and extend these models.

First, the present findings showed that intergroup threat is positively associated with different forms of positive beliefs about the ingroup, a specific aspect of ingroup identification (Leach 
et al., 2008). Second, the findings demonstrated that not only integrated threat but also distinctiveness threat predict higher collective narcissism and ingroup satisfaction, thus broadening the scope of the literature. The findings of both studies were similar, illustrating that both integrated and distinctiveness threats were positively related to both forms of ingroup positivity. Nonetheless, future research could further compare the relevance of different forms of threat for ingroup positivity. For instance, considering that distinctiveness threat focuses on the lack of distinction between the ingroup and the outgroup, it could be particularly relevant to predicting collective narcissism, which asserts the ingroup's superiority and uniqueness. Not being distinguishable from others is likely to be a relevant threat to those who believe their ingroup does not receive sufficient recognition from others (Golec de Zavala et al., 2019). Albeit similar in its direction, the association of distinctiveness threat with negative intergroup outcomes seemed weaker than the association of integrated threat with negative intergroup outcomes (i.e., smaller direct effect sizes). Although the current studies do not allow us to draw definitive conclusions on this issue, future research would do well to explore it further. Studies could compare the impact of different forms of threat using different outcome measures to capture not only outcomes such as outgroup derogation (e.g., negative emotions, hostility), but also negative intergroup differentiation more directly (e.g., through ingroup bias scores). Indeed, research shows that the effects of distinctiveness threat on intergroup differentiation are more pronounced on behavioral outcomes (such as greater reward allocations to the ingroup) than on trait evaluations or stereotyping (Jetten et al., 2004).

In addition, the negative intergroup consequences of intergroup threats were differentially mediated by collective narcissism and ingroup satisfaction. In both studies, collective narcissism mediated the positive associations between intergroup threat on the one hand and negative emotions and hostile behavioral intentions on the other. However, in both studies, we found a countervailing, independent association between intergroup threats and positive intergroup consequences via ingroup satisfaction. That is, ingroup satisfaction mediated the negative association between intergroup threat and negative emotions and hostile behavioral intentions. Thus, when considering the link between intergroup threats and intergroup relations, it is critical to account for the positive overlap between different forms of ingroup positivity and their opposite unique consequences for intergroup emotions and behaviors. As a momentous illustration of this difference from recent political history, collective narcissism accounted for the Brexit vote in the UK, whereas ingroup positivity in the form of national identification did not (Golec de Zavala et al., 2017). Similarly, collective narcissism was uniquely associated with lack of solidarity with conationals during the COVID-19 pandemic, whereas ingroup satisfaction predicted more solidarity (Federico et al., 2020). Nonetheless, future research could further explore the impact of threat on collective narcissism while controlling for its overlap with other subdimensions of ingroup identification, besides ingroup satisfaction (e.g., self-definition), as recent research documented differences in the association of personal control with, respectively, self-investment and self-definition when controlling for its overlap with collective narcissism (Marchlewska et al., 2020). Previous research also showed that different subcomponents of self-investment and self-definition (e.g., centrality vs. homogeneity) are differentially related to perceived threat to the ingroup (Leach et al., 2008), highlighting the importance of examining the potential differential impact of threat on diverse aspects of ingroup identification and ingroup positivity.

Our research has limitations. To begin, our studies were cross-sectional and thus unable to determine directionality, let along causality. It is possible, for example, that the relation between intergroup threat and ingroup positivity is bidirectional: higher levels of threat are associated with greater ingroup positivity, but the more one feels positively about the ingroup (i.e., the higher 
one's collective narcissism and ingroup satisfaction are), the more intergroup threat one perceives. These issues can be addressed with experimental and longitudinal designs.

Moreover, we offered no hypotheses regarding between-country differences, assuming crosscountry generality. Indeed, our findings replicated across the four countries: we obtained differences in effect sizes, but not in direction of the result patterns. Yet, follow-up investigations would need to expand the focus of our research to more EU countries, in search of sociocultural contexts that might make a difference. In addition, future studies could examine whether the association of different forms of ingroup positivity and intergroup hostility varies for threat-relevant versus nonrelevant (i.e., control) outgroups, considering that previous research showed that intergroup differentiation is stronger when ingroup versus outgroup categorization involves a relevant social comparison group (Lalonde, 2002), as it was the case in both Study 1 and Study 2. Finally, we did not account for the majority/minority ethnic status of our participants within each country. Considering for instance that majorities see themselves as more prototypical of the superordinate group (e.g., nation), the negative consequences of perceived threat, such as increased collective narcissism, could be stronger for majorities than minorities. Future work could further explore the potential moderating role of group status.

In conclusion, integrated and distinctiveness threats positively predicted collective narcissism and ingroup satisfaction, but only collective narcissism was linked to negative emotions and hostile behavioral intentions toward threatening outgroups after its overlap with ingroup satisfaction was partialled out. These findings were consistent across four countries, suggesting that intergroup threat is a robust predictor of collective narcissism in other national contexts, which ultimately could inform policies and strategies to tackle the well-known negative intergroup consequences of collective narcissism. The findings advance the theoretical understanding of predictors of collective narcissism, which has mostly been focused on individual-level variables (e.g., personal control, self-esteem), as well as on its consequences, and open up interesting directions of inquiry.

\section{Acknowledgements}

We thank Eirini Avgoustaki, Maria Bakarou, and Panayiota Metallidou for assistance with preparation of the Greek materials; Eirini Avgoustaki, Rozy Charitopoulou, Panagiotis Drepaniotis, Victoria Kanellopoulou, Paraskevi Kavalari, Alkistis Papazacharopoulou, John Sayas, and Sofia Zounidou for facilitating access to Greek participants; and Eirini Avgoustaki and Eleftheria Tseliou for helpful comments.

\section{Funding}

The author(s) disclosed receipt of the following financial support for the research, authorship, and/or publication of this article: This work was supported by Fundação para a Ciência e Tecnologia (FCT) with a grant awarded to Rita Guerra, Agnieszka Golec de Zavala, and Constantine Sedikides (PTDC/ MHC-PSO/0144/2014).

\section{ORCID iDs}

Rita Guerra (iD) https://orcid.org/0000-0003-3184 $-5164$

Georgios Abakoumkin (iD https://orcid.org/0000 $-0002-1671-3561$

\section{Supplemental material}

Supplemental material for this article is available online.

\section{Notes}

1. We conducted pilot studies in each country to identify the relevant outgroup for comparison in each national context and for each form of threat. Participants selected, from a list/map depicting all the European Union countries, which country was better/worse/similar/different to their country on three domains: (1) economic performance and status (realistic threat), (2) cultural values and traditions (symbolic threat), and (3) identity and uniqueness (distinctiveness threat). We then selected as relevant outgroups the countries that were indicated as having: (1) simultaneously different and better economic performance and status, (2) simultaneously different and worse 
cultural values and traditions, and (3) a similar identity.

2. Data collection took place on August 4, 2017 in Germany; between September 28 and November 7, 2017 in Greece; between June 7 and July 8, 2017 in Portugal; and on May 22, 2017 in the UK.

3. Studies 1 and 2 were part of a larger research project, and so they included measures irrelevant to the purposes of this article. These measures were subjective status of the country, indispensability, national identification centrality, European identification, blind and constructive patriotism, nostalgia, metaperceptions of humanness.

\section{References}

Aberson, C. L. (2019). Indirect effects of threat on the contact-prejudice relationship: A meta-analysis. Social Psychology, 50, 105-126. https://doi. org/10.1027/1864-9335/a000364

Bickes, H., Otten, T., \& Weymann, L. C. (2014). The financial crisis in the German and English press: Metaphorical structures in the media coverage on Greece, Spain and Italy. Discourse \& Society, 25, 424-445. https://doi. org/10.1177/0957926514536956

Branscombe, N. R., Ellemers, N., Spears, R., \& Doosje, B. (1999). The context and content of social identity threat. In N. Ellemers \& R. Spears (Eds.), Social identity: Contexts, commitment, content (pp. 35-59). Blackwell Science.

Branscombe, N. R., Schmitt, M. T., \& Harvey, R. D. (1999). Perceiving pervasive discrimination among African Americans: Implications for group identification and well-being. Journal of Personality and Social Psychology, 77, 135-149. https:// doi.org/10.1037/0022-3514.77.1.135

Breakwell, G. M. (1987). Identity. In H. Beloff \& A. Coleman (Eds.), Psychology survey 6 (pp. 94-114). British Psychological Society.

Byrne, B. M. (2001). Structural equation modeling with AMOS: Basic concepts, applications, and programming. Erlbaum.

Chang, L. W., Krosch, A. R., \& Cikara, M. (2016). Effects of intergroup threat on mind, brain, and behavior. Current Opinion in Psychology, 11, 69-73. https://doi.org/10.1016/j.copsyc.2016.06.004

Cichocka, A. (2016). Understanding defensive and secure in-group positivity: The role of collective narcissism. European Review of Social Psychology, 27, 283-317. https://doi.org/10.1080/10463283.20 16.1252530
Cichocka, A., Golec de Zavala, A., Marchlewska, M., Bilewicz, M., Jaworska, M., \& Olechowski, M. (2018). Personal control decreases narcissistic but increases non-narcissistic in-group positivity. Journal of Personality, 86, 465-480. https://doi. org/10.1111/jopy.12328

Cichocka, A., Marchlewska, M., Golec de Zavala, A., \& Olechowski, M. (2016). "They will not control us": Ingroup positivity and belief in intergroup conspiracies. British Journal of Psychology, 107, 556576. https://doi.org/10.1111/bjop.12158

Costello, K., \& Hodson, G. (2011). Social dominancebased threat reactions to immigrants in need of assistance. European Journal of Social Psychology, 41, 220-231. https://doi.org/10.1002/ejsp.769

Cottrell, C. A., \& Neuberg, S. L. (2005). Different emotional reactions to different groups: A sociofunctional threat-based approach to "prejudice." Journal of Personality and Social Psychology, 88, 770-789. https://doi.org/10.1037/00223514.88.5.770

Crocker, J., \& Luhtanen, R. (1990). Collective selfesteem and ingroup bias. Journal of Personality and Social Psychology, 58, 60-67. https://doi. org/10.1037/0022-3514.58.1.60

Dyduch-Hazar, K., Mrozinski, B., \& Golec de Zavala, A. (2019). Collective narcissism and in-group satisfaction predict opposite attitudes toward refugees via attribution of hostility. Frontiers in Psychology, 10, 1901. https://doi.org/10.3389/ fpsyg.2019.0190

Egleston, B. L., Miller, S. M., \& Meropol, N. J. (2011). The impact of misclassification due to survey response fatigue on estimation and identifiability of treatment effects. Statistics in Medicine, 30, 3560-3572. https://doi.org/10.1002/sim.4377

Federico, C. M., \& Golec de Zavala, A. (2018). Collective narcissism and the 2016 United States presidential vote. Public Opinion Quarterly, 82, 110-121. https://doi.org/10.1093/poq/nfx048

Federico, C. M., Golec de Zavala, A., \& Baran, T. (2020). Collective narcissism, in-group satisfaction, and solidarity in the face of COVID19. Social Psychological and Personality Science. Advance online publication. https://doi. org/10.1177/1948550620963655

Golec de Zavala, A. (2018). Collective narcissism: Antecedents and consequences of exaggeration of the in-group image. In A. Hermann, A. Brunell \& J. Foster (Eds.), Handbook of trait narcissism: Key advances, research methods, and controversies (pp. 7989). Springer. 
Golec de Zavala, A., \& Federico, C. M. (2018). Collective narcissism and the growth of conspiracy thinking over the course of the 2016 United States presidential election: A longitudinal analysis. European Journal of Social Psychology, 48, 1011-1018. https://doi.org/doi.org/10.1002/ejsp.2496

Golec de Zavala, A., Cichocka, A., \& Bilewicz, M. (2013). The paradox of in-group love: Differentiating collective narcissism advances understanding of the relationship between ingroup love and out-group attitudes. Journal of Personality, 81, 16-28. https://doi.org/10.111 1/j.1467-6494.2012.00779

Golec de Zavala, A., Cichocka, A., Eidelson, R., \& Jayawickreme, N. (2009). Collective narcissism and its social consequences. Journal of Personality and Social Psychology, 97, 1074-1096. https://doi. org/10.1037/a0016904

Golec de Zavala, A., Dyduch-Hazar, K., \& Lantos, D. (2019). Collective narcissism: Political consequences of investment of self-worth in the ingroup's image. Advances in Political Psychology, 40, 37-74. https://doi.org/10.1111/pops.12569

Golec de Zavala, A., Federico, C. M., Sedikides, C., Guerra, R., Lantos, D., Mroziński, B., Cypryanska, M., \& Baran, T. (2020). Low self-esteem predicts out-group derogation via collective narcissism, but this relationship is obscured by in-group satisfaction. Journal of Personality and Social Psychology, 119, 741-764. https://doi.org/10.1037/ pspp0000260

Golec de Zavala, A., Guerra, R., \& Simao, C. (2017). The relationship between the Brexit vote and individual predictors of prejudice: Collective narcissism, right wing authoritarianism, social dominance orientation. Frontiers in Psychology, 8, Article 2023. https://doi.org/10.3389/fpsyg.2017.02023

Golec de Zavala, A., \& Lantos, D. (2020). Collective narcissism and its social consequences: The bad and the ugly. Current Directions in Psychological Science, 29, 273-278. https://doi. org $/ 10.1177 / 0963721420917703$

Golec de Zavala, A., Peker, M., Guerra, R., \& Baran, T. (2016). Collective narcissism predicts hypersensitivity to in-group insult and direct and indirect retaliatory intergroup hostility. European Journal of Personality, 30, 532-551. https://doi.org/10.1002/ per.2067

Jaworska, M. (2016). Caym jest dojrzata identyfikacja z grupa? W poszukiwaniu komponentón identyfikacji grupowej majacych posytymne konsekwencje dla grupy wlasnej $i$ relacie miedrygruponych [What is secure in-group identification? Looking for in-group identification components that lead to ingroup's benefit and positive intergroup relations] [Unpublished doctoral dissertation]. University of Warsaw.

Jetten, J., \& Spears, R. (2003). The divisive potential of differences and similarities: The role of intergroup distinctiveness in intergroup differentiation. European Review of Social Psychology, 14, 203-241. https://doi.org/10.1080/10463280340000063

Jetten, J., Spears, R., \& Manstead, A. S. (2001). Similarity as a source of differentiation: The role of group identification. European Journal of Social Psychology, 31, 621-640. https://doi.org/10.1002/ ejsp. 72

Jetten, J., Spears, R., \& Postmes, T. (2004). Intergroup distinctiveness and differentiation: A meta-analytic integration. Journal of Personality and Social Psychology, 86, 862-879. https://doi: 10.1037/0022-3514.86.6.862

Kenny, D. A., Kaniskan, B., \& McCoach, D. B. (2015). The performance of RMSEA in models with small degrees of freedom. Sociological Methods \& Research, 44, 486-507. https://doi. org/10.1177/0049124114543236

Krosnick, J. A., \& Presser, S. (2010). Question and questionnaire design. In J. D. Wright \& P. V. Marsden (Eds.), Handbook of survey research (2nd ed., pp. 263-313). Emerald Group.

Lalonde, R. N. (2002). Testing the social identity-intergroup differentiation hypothesis: 'We're not American eh!'. British Journal of Social Psychology, 41, 611-630. https:// doi.org/10.1348/014466602321149902

Leach, C. W., van Zomeren, M., Zebel, S., Vliek, M. L. W., Pennekamp, S. F., Doosje, B., Ouwerkerk, J. W., \& Spears, R. (2008). Grouplevel self-definition and self-investment: A hierarchical (multicomponent) model of in-group identification. Journal of Personality and Social Psychology, 95, 144-165. https://doi.org/10.1037/00223514.95.1.144

Lyons, P. A., Kenworthy, J. B., \& Popan, J. R. (2010). Ingroup identification and group-level narcissism as predictors of US citizens' attitudes and behavior toward Arab immigrants. Personality and Social Psychology Bulletin, 36, 1267-1280. https://doi. org/10.1177/0146167210380604

Mackie, D. M., Devos, T., \& Smith, E. R. (2000). Intergroup emotions: Explaining offensive action 
tendencies in an intergroup context. Journal of Personality and Social Psychology, 79, 602-616. https:/ / doi.org/10.1037/0022-3514.79.4.602

MacKinnon, D. P., Krull, J. L., \& Lockwood, C. M. (2000). Equivalence of the mediation, confounding and suppression effect. Prevention Science, 1, 173-181. https://doi. org/10.1023/A:1026595011371

Marchlewska, M., Cichocka, A., Jaworska, M., Golec de Zavala, A., \& Bilewicz, M. (2020). Superficial in-group love? Collective narcissism predicts ingroup image defense, outgroup prejudice and lower in-group loyalty. British Journal of Social Psychology. Advance online publication. https://doi. org/10.1111/bjso.12367

Marchlewska, M., Cichocka, A., Panayiotou, O., Castellanos, K., \& Batayneh, J. (2018). Populism as identity politics: Perceived in-group disadvantage, collective narcissism, and support for populism. Social Psychological and Personality Science, 9, 151-162. https://doi.org/10.1177/1948550617732393

Obaidi, M., Kunst, J. R., Kteily, N., Thomsen, L., \& Sidanius, J. (2018). Living under threat: Mutual threat perception drives anti-Muslim and antiWestern hostility in the age of terrorism European Journal of Social Psychology, 48, 567-584. https:// doi.org/10.1002/ejsp.2362

Paulhus, D. L., Robins, R. W., Trzesniewski, K. H., \& Tracy, J. L. (2004). Two replicable suppressor situations in personality research. Multivariate Behavioral Research, 39, 301-326. https://doi. org/10.1207/s15327906mbr3902_7

Petropoulos, N., \& Tsobanoglou, G. O. (Eds.). (2014). The debt crisis in the Eurozone: Social impacts. Cambridge Scholars Publishing.

Polyakova, A., \& Fligstein, N. (2016). Is European integration causing Europe to become more nationalist? Evidence from the 2007-9 financial crisis. Journal of European Public Policy, 23, 60-83. https:// doi.org/10.1080/13501763.2015.1080286

Preacher, K. J., \& Hayes, A. F. (2008). Asymptotic and resampling strategies for assessing and comparing indirect effects in multiple mediator models. Behavior Research Methods, 40, 879-891. https:// doi.org/10.3758/BRM.40.3.879

Preacher, K. J., Rucker, D. D., \& Hayes, A. F. (2007). Addressing moderated mediation hypotheses: Theory, methods, and prescriptions. Multivariate Behavioral Research, 42, 185-227. https://doi. org/10.1080/00273170701341316
Riek, B. M., Mania, E. W., \& Gaertner, S. L. (2006). Intergroup threat and outgroup attitudes: A meta-analytic review. Personality and Social Psychology Review, 10, 336-353. https://doi.org/10.1207/ s15327957pspr1004_4

Rosseel, Y. (2012). Lavaan: An R package for structural equation modeling. Journal of Statistical Software, 48, 1-36. Retrieved from http://www.jstatsoft.org/ v48/i02/

Ryu, E., \& Cheong, J. (2017). Comparing indirect effects in different groups in single-group and multi-group structural equation models. Frontiers in Psychology, 8, Article 747. https://doi. org/10.3389/fpsyg.2017.00747

Schild, J. (2020). The myth of German hegemony in the Euro area revisited. West European Politics, 43, 1072-1094. https://doi.org/10.1080/01402382. 2019.1625013

Schmid, K., Hewstone, M., Tausch, N., Cairns, E., \& Hughes, J. (2009). Antecedents and consequences of social identity complexity: Intergroup contact, distinctiveness threat, and outgroup attitudes. Personality and Social Psychology Bulletin, 35, 1085-1098. https://doi. org/10.1177/0146167209337037

Schmid, K., \& Muldoon, O. T. (2015). Perceived threat, social identification, and psychological well-being: The effects of political conflict exposure. Political Psychology, 36, 75-92. https://doi.org/10.1111/ pops. 12073

Schoeller, M. G. (2017). Providing political leadership? Three case studies on Germany's ambiguous role in the Eurozone crisis. Journal of European Public Policy, 24, 1-20. https://doi.org/10.1080/135017 63.2016.1146325

Schönbrodt, F. D., \& Perugini, M. (2013). At what sample size do correlations stabilize? Journal of Research in Personality, 47, 609-612. https://doi. org/10.1016/j.jrp.2013.05.009

Stephan, W. G., Boniecki, K. A., Ybarra, O., Bettencourt, A., Ervin, K. S., Jackson, L. A., McNatt, P. S., \& Renfro, C. L. (2002). The role of threats in the racial attitudes of Blacks and Whites. Personality and Social Psychology Bulletin, 28, 1242-1254. https://doi. org/10.1177/01461672022812009

Stephan, W. G., Ybarra, O., \& Morrison, K. R. (2009). Intergroup threat theory. In T. D. Nelson (Ed.), Handbook of prejudice, stereotyping, and discrimination (pp. 43-59). Psychology Press. 
Tahir, H., Kunst, J. R., \& Sam, D. L. (2019). Threat, anti-Western hostility and violence among European Muslims: The mediating role of acculturation. International Journal of Intercultural Relations, 73, 74-88. https://doi.org/10.1016/j. ijintrel.2019.08.001

Tajfel, H., \& Turner, J. C. (1979). An integrative theory of intergroup conflict. In W. G. Austin \& S. Worchel (Eds.), The social psychology of intergroup relations (pp. 33-37). Brooks/Cole.
Vasilopoulou, S., Halikiopoulou, D., \& Exadaktylos, T. (2014). Greece in crisis: Austerity, populism and the politics of blame. Journal of Common Market Studies, 52, 388-402. https://doi.org10.1111/ jcms.12093

Vignoles, V. L., Chryssochoou, X., \& Breakwell, G. M. (2000). The distinctiveness principle: Identity, meaning, and the bounds of cultural relativity. Personality and Social Psychology Review, 4, 337-354. https://doi.org/10.1207/S15327957PSPR0404_4 